\title{
General Agreement on Trade in Services and the health sector
}

\section{B EKBAL}

National Convenor, People's Health Movement India (Jan Swasthya Abhyiyan) Kuzhuvalil House, Arpookara East, Kottayam 686008 Kerala INDIA email: ekbal@vsnl.com

\begin{abstract}
Until the World Trade Organization emerged in 1995, there was no multilateral agreement on services. Negotiations at the WTO led to the General Agreement on Trade in Services, a comprehensive agreement on the international trade in services. GATS explicitly provides for successive rounds of negotiation with a view to achieving a progressively higher degrees of liberalisation. An increase in trade in health services offers a handful of developing countries a limited set of export opportunities, predominantly in attracting foreign consumers to their health facilities. These gains seem trivial when compared with the effects that the increased trade in health services could have on people's right to health. Trade in health services risks exacerbating many of the problems which already plague health systems across the world. The damage may outweigh the benefits, particularly for those with little ability to pay more for publicly provided health care.
\end{abstract}

The last round of the General Agreement on Tariffs and Trade (GATT) in 1994 gave rise to a multilateral agreement on trade under the World Trade Organization (WTO). The WTO identified two areas for multilateral agreement: goods and merchandise, and trade in services.

Until the WTO emerged in 1995, there was no multilateral agreement on services. Some services were exchanged but no arrangement existed for trade in services. Services tend to be place specific and were considered non-tradable. By the 1990s services constituted a major part of the economy of some countries and became an important portion of international trade.

Negotiations at the WTO led to a comprehensive agreement on the international trade in services. The objective of this agreement is progressive liberalisation of trade in services. It aims to provide a secure and more open market in services like the GATT does for trade in goods. The resultant document is the General Agreement on Trade in Services (GATS). GATS explicitly provides for successive rounds of negotiation with a view achieving a progressively higher degrees of liberalisation.

This agreement covers several services, specified in 19 categories, including services related to health and education. It provides the legally enforceable right to trade in all services. Only those services provided entirely by the government don't fall within GATS rule. When the services are provided either partially by the government or provided by private providers, as is the case for the health sector in India, they come under GATS. Any institution that requires a payment or fee falls under GATS.

\section{The scope of GATS}

Article I, Paragraph 3 of GATS defines the scope of the agreement as follows:

(b) "Services" includes any service in any sector except services supplied in the exercise of governmental authority. It may appear therefore that in countries where health care is mostly provided by government may be exempted from implementing GATS in the health sector." However the article further clarifies that (c) "a service supplied in the exercise of governmental authority," means any service that is supplied neither on a commercial basis nor in competition with one or more service suppliers. In most countries health services are also provided by the private sector and even the government sector charges for certain services. Therefore, under these sections of the agreement, the health sector is invariably covered by GATS. Unlike many other services, however, the direct impact of liberalisation on the priorities of the public health sector makes this kind of trade a critical issue in terms of people's right to health.

Under GATS, supply can take four modes: one, Cross Border Supply, where the service is provided remotely from one country to another (e.g., international telephone calls, Internet services, telemedicine); two, Consumption Abroad, where individuals use a service in another country (e.g. tourists travelling abroad, patients taking advantage of health care in foreign countries); three, Commercial Presence, where a foreign company sets up a subsidiary or branch within another country in order to deliver the service locally (e.g. banks, private health clinics); four, Presence of Natural Persons: where individuals travel to another country to supply a service there on a temporary basis (e.g. software programmers, nurses, doctors).

\section{Modes of supply under GATS: cross border supply}

The most important example of cross border supply or trade in health services is telemedicine:the provision of medical services from a practitioner in one country to a patient or practitioner in another, predominantly via the Internet or satellite transmission of medical images. While still at an early stage, the potential benefits of telemedicine are already evident, especially for remote diagnosis and treatment. Based on evidence of its use among remote rural communities in Japan and Australia, telemedicine could expand the capacities of doctors in developing countries. 
But the effective implementation of telemedicine projects presupposes a communications infrastructure developed to a level far higher than is currently found in most remote areas of the developing world. However several examples already exist of non-commercial telemedicine projects working within developing countries on an experimental basis. While a growing body of evidence attests to the clinical benefit and cost effectiveness of telemedicine, there is less proof of its commercial sustainability.

Telemedicine includes the remote provision of medical education. Teleconferencing has already been established between institutions in Canada, Kenya and Uganda to enable health care workers in Africa to benefit from the latest medical knowledge. Internet sites such as the University of lowa's Virtual Hospitals provide free online information on a wide range of adult and child health problems - a valuable resource for doctors otherwise reliant upon outdated collections of medical journals. In all these cases, the expansion of cross-border supply of telemedicine offers potential gains for health care. However, concerns remain about the confidentiality of patients and the applicability and relevance of medical information generated in industrialised countries to situations in the developing world.

In addition, there is the problem of regulatory control over telemedicine, as noted by the $50^{\text {th }}$ World Health Assembly in its 1997 resolution on the uncontrolled sale of prescription drugs over the Internet. The resolution focused on the public health hazard of counterfeit products being passed off as genuine, and on the inappropriate use of potentially dangerous medicines without medical supervision. (The WHO had already exposed four companies selling prescription drugs over the Internet without the detailed information that should accompany the sales).Telemedicine poses regulatory challenges on the demand as well as the supply side. Even the most advanced regulatory systems will be unable to prevent doctors or clinics from ordering medicines over the Internet which are not included in a country's essential drugs list. Such practices might give those practitioners a perceived commercial edge over rivals who keep within treatment guidelines, but would undermine national policies promoting the rational use of drugs.

The potential drain which commercial cross-border trade in telemedicine could have on limited health care budgets in developing countries is also a matter of great concern. At present almost all trade in remote health care is from North to South, and the expense of entering into commercial relationships would be prohibitive for poorer nations. While the technology of telemedicine offers potential benefits in some cases, few would suggest its commercial development offers more general solutions to the health problems of the majority.

Of more immediate significance is the development of crossborder private medical insurance and managed health care. Private health insurance is mostly provided by companies with a commercial presence in the country (and thus covered by mode three, or Commercial Presence, under GATS), and the potential is increasing for such services to be provided across national borders. However, the issues remain substantially the same as those discussed later in connection with mode three: the increased commercialisation of health care and the growing involvement of the private sector.

\section{Modes of supply under GATS: consumption abroad}

Patients consuming medical services abroad represent a more significant source of international trade in health services. They may have travelled abroad especially to seek medical treatment in another country or happen to need treatment while visiting that country for other reasons. The majority of the USA's estimated $\$ 872$ million in health care exports in 1996 came from foreigners being treated in the country.

The potential for developing countries to gain economic benefit from attracting foreign consumption of their health services is limited. However, certain countries have identified the provision of health services to foreigners as a potential growth area. India offers significant cost advantages for patients travelling from industrialised countries, with major treatments such as liver transplants or coronary bypass surgery priced at a tenth of what individuals would be charged in the USA. In addition, certain countries offer culturally specific health services. Traditional medicine draws a substantial number of patients to China every year, the majority of them overseas Chinese but also a growing number of individuals who have turned away from the western medical tradition. India has a similar advantage in its extensive network of ayurvedic practitioners, who attract a steady trickle of foreigners every year. States like Kerala are already encouraging health tourism based on traditional knowledge.

Another aspect of consumption of health services abroad is the training of medical students at foreign educational institutions. Countries such as the UK and USA have long traditions of providing such education to foreign students on a commercial basis. Certain countries have the ability to attract foreign students for culturally specific courses, such as training in ayurvedic or traditional Chinese medicine. Some German universities now give students credits for courses taken in institutions in China. In these limited cases, the consumption of domestic services by foreigners represents a potential source of export earnings for the host countries.

However, these benefits will be outweighed by the social costs if limited investment is drawn away from national health priorities. In the vase majority of countries, an expanding private sector will draw medical personnel away from the public sector. Favouring foreign patients will come at the expense of the local population. While extra investment financed by charges on foreign consumers has the potential to upgrade services for local users, in practice the two groups often use separate facilities, with little opportunity for crossovers. Worse still, the public sector often has to bear the cost of building the new hospitals and clinics to treat foreign patients, which is a further diversion of resources away from public health needs.

A lesser threat applies to those countries which provide education to foreign medical students, given that there is greater elasticity of supply than in the case of health care. However, the economic imperative to raise numbers of paying 
foreign students has the potential to drive down the quality of training as a result of declining teacher to student ratios and rising pressure on resources.

Ultimately there may emerge a parallel threat to that experienced by patients: reduced opportunity of access for domestic students and a consequent contraction in the numbers of qualified nationals. The reverse situation pertains for those countries which send medical students for training abroad. In such cases the training represents an import in balance of payment terms, but can be seen as an investment in terms of the obvious potential for skills transfer. However, the extent to which those skills can be deployed to the benefit of the wider society depends on how many of the trainees return to their home country once their courses are over. Only half of the Indian doctors trained in Europe and the USA return home at the end of their training.

\section{Modes of supply under GATS: commercial presence}

The establishment of commercial presence in a foreign country differs from the other three modes of GATS in that it is essentially an issue of investment. In health care, this investment relates primarily to foreign commercial presence in hospitals, health clinics and health insurance, and to a lesser extent to the provision of medical education. As noted, GATS aims to generate new opportunities for companies to invest and operate in the service sectors of other countries. But the prospect of increased foreign commercial presence in the health sector has raised serious concerns about people's right to health, given the negative experience of fees in the sector.

In developing countries, much of this experience has come as a result of the liberalisation process, which has involved structural adjustment programmes under the IMF and the World Bank. The introduction of cost recovery programmes in the health sector is now widely accepted to have been disastrous, forcing many poor families and their children into a "medical poverty trap" characterised by untreated illness and long-term impoverishment. Even the World Bank, while it continues to support user fees for health in it national poverty-reduction strategy papers, has acknowledged that they are responsible for denying poor families access to health care.

Structural adjustment programmes have introduced cost recovery principles into the health care sector in many countries. Yet GATS goes one stage further, as it represents the commodification of health care for trade on the open market.Just as internal liberalisation prepares the way for commercialisation of the health sector, so too external liberalisation locks in commercialisation through the long-term presence of foreign investment.

For developing countries with failing health systems, this foreign investment may seem an attractive source of capital and medical technology at a time when other sources are thin on the ground. Yet involvement by the foreign private sector in health care has the potential to marginalise the poor even further. Companies seek markets in which they can be assured sufficient returns, and this typically concentrates investment in more affluent areas. Loans granted to private health care providers by the World Bank's International Finance Corporation, for instance, are predominantly directed towards facilities for the richer communities of the country or for expatriates, not the majority of the population. This practice of "cream skimming" by the private sector is already familiar in the field of private health insurance, where insurance companies and health maintenance organisations (HMOs) typically favour the healthy and wealthy over high-risk customers, excluding the latter by means of prohibitive premiums.

In terms of direct health care provision, similarly, the private sector's profit-making imperative limits its relevance to those sections of society which are unable to pay for its services, even though it is they who need the extra investment the most. Yet private investment in health care is not irrelevant to poor people. In many countries, as noted, an expanding private sector will draw personnel away from public health systems and exacerbate shortages of trained and qualified staff. Often it is the most skilled staff that makes the move to the private sector, lowering the overall quality of personnel in the public health system. Worse still, cream skimming undermines the very ability of public health systems to sustain themselves financially, as it denies the basic principles of cross-subsidisation and riskpooling by which the healthy support the ill, the young the old and the rich the poor:

Foreign investment also brings with it the risk of domination by transnational corporations to the exclusion of domestic development. In the hospital sector, the overwhelming majority of these corporations are powerful companies based in Europe and the USA. Only Singapore's Parkway Holdings and South Africa's Afrox Healthcare are exceptions.

As well as the equity issues raised by commercialisation, liberalisation also risks compromising the quality of health care delivery. The introduction of private sector companies into public health systems raises potential conflicts of interest between commercial pressures and public health goals. In industrialised countries this has commonly meant a reduction in quality as a result of cost cutting, often through a substitution of casual for skilled labour amongst nursing and ancillary staff. It has also led to the planning of hospitals on the basis of financial rather than clinical need, with accompanying reductions in the clinical workforce and service capacity.

In the USA, where the health care market has become increasingly competitive over time, HMOs have responded by pressurising doctors to withhold treatment from their patients. By means of performance-related pay mechanisms linking their incomes directly to the clinical costs they incur, doctors are encouraged to refer the lowest possible number of patients to specialists or to hospitals. The HMO awards bonuses to those who minimise such expenditure, while doctors who generate above-average costs risk expulsion.

In developing countries, commercial pressures lead to similar profit maximisation strategies. One study of private clinics in Malaysia revealed that many fail to assess new clients properly in 
their provision of family panning services, and cervical screening is undertaken only if requested. Conversely, private practitioners in Egypt have been found to be less likely than public sector workers to administer (inexpensive) oral rehydration solution, and more likely to prescribe anti-diarrhoeal drugs even though the latter are contraindicated in the country's national programme.

The decision to involve foreign companies in the health sector requires very definite structural conditions if it is not to damage the quality of health care delivery in systems which are already under severe strain. As many commentators have stressed, national and regional health authorities need highly developed regulatory, analytical and managerial capacity if they are to see any benefit from the challenges of working with foreign companies.

In the majority of poorer countries, however, this capacity is simply non-existent. As a result, the introduction of private sector investment threatens to divert care away from public health priorities and to further compromise the quality of health care delivery. Concerns that profit-led health care is excessively focused on curative rather than preventive measures are familiar and longstanding, as are fears of over-prescription and unnecessary treatment undertaken for financial motives. Even joint public-private initiatives based on donations or price discounts have revealed their own shortcomings, distorting national health strategies and diverting funds towards nonpriority areas, as well as hindering the development of national health systems as a whole. The acknowledged difficulties of integrating private sector companies into public health care have sown doubts among even the most pro-liberalisation commentators.

Moreover,as far as the objectives of health services are concerned, the efficiency of the private sector is unsubstantiated. Patterns of health care consumption resemble those for luxury goods, with high-income households spending a higher proportion of their income on health care than poor households. Poor households therefore account for the majority of health needs but a disproportionately minority share of health expenditure, so that the use of resources in the private health care market is doubly skewed away from need. Precisely this inverted relation between supply and demand renders the market inefficient.

\section{Modes of supply under GATS: presence of "natural persons"}

If the establishment of commercial presence is primarily of interest to transnational corporations from industrialised countries, the temporary movement of "natural persons" to provide a service abroad has generated most interest among developing countries. There is already substantial movement of medical personnel from South to North and between countries of the developing world (health services, unlike many other professional services, being largely based on universal principles). However, the perceived economic benefits of this trade raise serious concerns about people's right to health, especially in the poorest countries.
The potential for exchange of medical personnel between countries is attested by experience from across the world. Developing countries - particularly in Asia - supply over half of all migrating physicians, with about 100,000 doctors of Indian origin settled in the USA and UK alone. Active international recruitment by national health systems has generated a particularly high level of cross-border mobility among nurses. A large number of countries which export doctors or nurses experience severe shortages themselves, and can ill afford to send their services abroad. Increased trade in health services risks exacerbating this transfer of medical personnel from poor to rich countries, thereby placing an even greater strain on health systems in the poorest. Since these are often the countries with the most acute health crises, the public health consequences of expanded trade can be considerable. Weighed against these losses, the remittances that medical personnel send home and the enhanced skills they bring with them if and when they return are poor compensation.

\section{Trade in water and sanitation}

In addition to trade in health care, trade in water and sanitation services also raises significant issues for people's right to health. In India the Pepsi and Coca Cola companies have already been marketing "mineral water."Here there are no balance of payment incentives encouraging developing countries to engage in increased trade: almost all the transnational corporations in the water and sanitation sectors are European and none are from the developing world. Clean water and proper sanitation facilities play a particularly important role in maintaining health during infancy and early childhood. Yet 1.1 billion people across the developing world still lack access to safe drinking water and 2.4 billion people - two fifths of the world's population - do not have adequate sanitation. As a result, more than two million children die from sanitation-related diseases every year.

As with health care, commercialisation has further restricted poor families' access to water and sanitation in many parts of the world. Cost recovery and water privatisation schemes have typically involved significant price rises, often putting water beyond the reach of low-incomehouseholds.Such developments raise similar problems of equity to those encountered in health care - except that with water, as with education, demand for the service is continual, not intermittent.

\section{Most Favoured Nation and national treatment}

Apart from the problems discussed above regarding the various modes of supply, there are other provisions in GATS that can adversely affect the interests of poorer nations. According to the WTO agreement, if favoured treatment is given to one country it should be extended to all the countries which have signed the agreement under WTO. The principle is: favour one, favour all. Most Favoured Nation means treating each trading partner equally. Under this provision of the GATT, if a country allows foreign competition in a sector, equal opportunities in that sector should be given to service providers from other WTO member countries. This in effect means that a country cannot be selective in permitting a foreign country in offering services based on its national interest. 
The principle of National Treatment relates to treating one's own nationals and foreigners equally. In services, it implies that once a foreign service provider has been allowed to provide a service in one country there should be no discrimination between foreign service supplier and the national/local service provider. For example, if a foreign group is allowed to set-up a hospital in India, it should be given the same treatment that is given to national/local health service providers in the country. This means that they may have to be given all the facilities like the subsidies a national institution is entitled to. Since the public health system is already starving for funds this provision can further take away the meagre government funds they receive. In this situation the easier option for the government would be to withdraw subsidy altogether from public sector.

\section{Balance sheet: meagre gains, high risks}

GATS aims to increase the global trade in services with progressive liberalisation. An increase in trade in health services offers a handful of developing countries a limited set of export opportunities, predominantly in attracting foreign consumers to their health facilities and in sending their own health professionals abroad. Yet these gains look trivial when compared with the effects which increased trade in health services could have on people's right to health. While there may be individual cases in which patients benefit from the development of telemedicine, the potential impacts of increased trade in health services are overwhelmingly negative. If developing countries divert health care resources and personnel towards foreign consumers for the sake of balance of payment gains, whether in their own health facilities or abroad, it can only lead to increased pressure on health systems which in most countries are already overstretched.

Attracting foreign investment in the health, water and sanitation sectors may initially seem like a more promising option. Yet the commercial presence of private sector companies is unable to address the central problems of access and quality, which challenge health, water and sanitation systems across the world. Instead of adding extra capacity to beleaguered public services, the private sector threatens to undermine them by taking over the most profitable parts of the system and drawing key personnel away from the public sector. In addition, it threatens to increase existing inequalities, given that the poor are commonly excluded from services provided on a commercial basis.

Trade in health services, then, risks exacerbating many of the problems, which already plague health systems across the world. The main thrust of GATS towards increasing trade and greater liberalisation seems inappropriate for the health sector and the damage may outweigh the benefits, particularly for those with little ability to pay more for publicly provided health care.

\section{Recommendations and conclusion}

Several organisations like Save the Children, Medicines Sans Frontiers, the International Peoples Health Council, Oxfam etc., have responded to the challenges posed by developing countries and the poor in the developed countries in relation to GATS and have suggested recommendations. These include a full and independent impact assessment of GATS and other
WTO agreements, recognition of national sovereignty over liberalisation commitments, stronger exemption for public services and exemption of subsidies from national treatment standards.

The expansion of trade liberalisation poses serious challenges to people's right to health. While some people may benefit from the increased economic opportunities which globalisation brings, many more stand to remain marginalised from its gains. Communities whose food security is undermined by exposure to international markets are directly at risk from increased trade liberalisation, and measures must be taken - in the context of the Agreement On Agriculture and elsewhere - to protect their livelihoods. As all commentators acknowledge, it is the most vulnerable who are most at risk.

Increased trade in health services offers meagre economic benefits to a handful of developing countries.Diverting resources and personnel towards foreign consumers threatens to put extra pressure on health systems which in many countries are already at breaking point. The commercial presence of transnational health corporations risks exacerbating existing problems of equity, quality and capacity. Given the low level of regulatory capacity in many countries, increased foreign investment in the health sector may well be a poisoned chalice. These conclusions argue against the suitability of the trade liberalisation model for basic services as a whole.

An international call for a full and independent assessment of GATS and trade in services is necessary. In view of the effective irreversibility of GATS-related market access and national treatment commitments, countries should not come under pressure to liberalise their basic services. Developing countries, in particular, should avoid making liberalisation commitments on basic services under GATS. A reassessment of GATS should form part of a wider review of WTO agreements, a review called for by the government of developing countries and civil society organisations around the world.

\section{References}

1. Adlung R, Carzaniga A. Health services under the General Agreement on Trade in Services. Bull World Health Organ 2001; 79:352-364.

2. Chadha T.GATS and developing countries: a case study of India.In:Stern RM, editors. Services in the international economy. Ann Arbor: University of Michigan Press; 2001.

3. Cornia GA. Globalization and health: results and options. Bull World Health Organ 2001; 79:834-841.

4. Edworthy SM.Telemedicine in developing countries.BMJ 2001;323:524525.

5. Gupta I, Goldar B, Mitra, A.The case of India. In:Zarilli S, Kinnon C, editors. International trade in health services: a development perspective. Geneva: UNCTAD / WHO; 1998.

6. Hilary J. The wrong model: GATS, trade liberalization and children's right to health. London: Save the Children; 2001.

7. Mandil SH. TeleHealth: what is it? Will it propel cross-border trade in health services? In:Zarilli S, Kinnon C, editors. International trade in health services: a development perspective. Geneva:UNCTAD/ WHO; 1998.

8. Oxfam. Dare to lead: public health and company wealth. Briefing paper on Glaxo Smith Kline. Oxford: Oxfam; 2001.

9. Price D, Pollock A, Shaoul J. How the World Trade Organisation is shaping domestic policies in health care. Lancet 1999; 354: 1889-1892.

10. Sexton S. Trading health care away? GATS, public services and privatisation. Sturminster Newton:The Corner House; 2001.

11. UNICEF The State of the World's Children 2001. New York: UNICEF; 2001. 
12. Waskow D, Yu VPB. A disservice to the Earth: The environmental impact of the WTO General Agreement on Trade in Services (GATS). Washington DC: Friends of the Earth USA; 2001.

13. Watkins K. Cost-recovery and equity in the health sector: issues for developing countries. Oxford: Oxfam; 1997

14. Whitehead M, Dahlgren G, Evans T. Equity and health sector reforms: can low-income countries escape the medical poverty trap? Lancet 2001; 358: 833-836.

15. WHO/ UNICEF Joint Monitoring Programme for Water Supply and Sanitation. Global water supply and sanitation assessment 2000 report. Geneva /New York:WHO/ UNICEF; 2000.

16. Wootton T. Recent advances: telemedicine. BMJ 2001; 323:557-560

\section{INDIAN JOURNAL OF MEDICAL ETHICS}

The Indian Journal of Medical Ethics carries original articles, reports, comments, case studies and other material on a range of issues related to health care ethics in developing countries, with special reference to India. Some of these:

- Corruption among medical professionals • Ethics education during medical college $\bullet$ Issues in high-technology medicine - Problems of research among poor populations $\bullet$ Contraceptive research and population policies.

In order to engage people in debates on health and medical practice, IJME encourages comments from all points of view. Some debates in recent issues:

- Is it right to perform pre-implantational genetic diagnosis for sex selection? $\bullet$ Is ECT without anaesthesia unethical? $\bullet$ May doctors refuse to treat people with HIV? • Should doctors advertise?

IJME is owned and published by the Forum for Medical Ethics Society, a not-for-profit, voluntary organisation in Mumbai, India. The FMES was born out of an effort by a group of concerned doctors to focus attention on the need for ethical norms and practices in health care.

\section{Subscribe to IJME and participate in the debate.}

\section{If you're already a subscriber, why don't you gift a subscription to a friend?}

$\downarrow$ Demand drafts /cheques should be in the name of 'Indian Journal of Medical Ethics'.

$\downarrow$ Please add Rs 30 for out-station cheques (US\$2 for international subscriptions).

- Personal subscriptions paid from personal funds are available at $\mathbf{5 0} \%$ discounted rates.

- Subscribers from other SAARC countries (Bangladesh, Bhutan, Maldives, Nepal, Pakistan and Sri Lanka) please pay the Indian rates adding Rs 100 per year extra for postage.

\ Special one-year subscriptions for Rs $\mathbf{1 5 0}$ are available to students in India.

\section{Subscription rates}

\begin{tabular}{|l|c|c|c|c|}
\hline & \multicolumn{2}{|c|}{ Indian } & \multicolumn{2}{c|}{ International } \\
\hline & Individual & Institutional & Individual & Institutional \\
\hline One year & Rs 250 & Rs 500 & US\$20 & US\$40 \\
\hline Two years & Rs 450 & Rs 900 & US\$35 & US\$70 \\
\hline Five years & Rs 1,000 & Rs 2,000 & US\$80 & US\$160 \\
\hline Life & Rs 10,000 & Rs 20,000 & & US\$1,600 \\
\hline
\end{tabular}

$\downarrow$ Please send your subscriptions and subscription queries to: Indian Journal of Medical Ethics, C/o CSER, Candelar, 4th Floor, 26 St John Baptist Road, Bandra (W), Mumbai 400050 INDIA e-mail: fme@vsnl.net 